\title{
Multiplex Immunoassays of Plant Viruses Based on Functionalized Upconversion Nanoparticles Coupled with Immunomagnetic Separation
}

\author{
Mingzhe Zhang, ${ }^{1}$ Wujian Chen, ${ }^{1}$ Xi Chen, ${ }^{1}$ Yongjiang Zhang, ${ }^{2}$ Xiaojia Lin, \\ Zhiyi $\mathrm{Wu}^{1}{ }^{1}$ and Mingfu $\mathrm{Li}^{2}$ \\ ${ }^{1}$ Zhejiang Entry-Exit Inspection and Quarantine Bureau, Hangzhou 310016, China \\ ${ }^{2}$ Chinese Academy of Inspection and Quarantine, Beijing 100029, China
}

Correspondence should be addressed to Mingzhe Zhang; mzzhang429@163.com

Received 16 July 2013; Revised 12 September 2013; Accepted 14 October 2013

Academic Editor: William W. Yu

Copyright (C) 2013 Mingzhe Zhang et al. This is an open access article distributed under the Creative Commons Attribution License, which permits unrestricted use, distribution, and reproduction in any medium, provided the original work is properly cited.

A sensitive, specific and rapid method for the detection of three different kinds of plant viruses including tomato ringspot virus (ToRSV), bean pod mottle virus (BPMV) and arabis mosaic virus (ArMV) was demonstrated using novel upconversion nanoparticles (UCNPs) as a fluorescence marker coupled with immunomagnetic separation. Magnetic nanoparticles (MNPs, $100 \mathrm{~nm})$ were coated with different antibodies were employed to capture and enrich the target viruses. Then antibody-conjugated UCNPs as signal probes were added to form sandwich complexes. This was followed by a fluorescence measurement using a $980 \mathrm{~nm}$ laser. This method not only avoids the difficulty in simultaneous detection of multiple independent organic fluorphores that require distinct excitation wavelengths, and auto-fluorescence of biological samples due to the higher-energy excitation of QDs but also amplifies detection signal by UCNPs-tags together with easy separation of samples by magnetic forces, demonstrating the potential to be used for detecting virus in the field of environmental safety and other fields.

\section{Introduction}

There is increasing interest in the development of nanotechnology for bioassay $[1,2]$. In the past two decades, optical and magnetic materials have attracted much attention due to their importance in the fields of chemistry, biology, medical sciences, and biotechnology [3].

$\mathrm{Fe}_{3} \mathrm{O}_{4}$ nanoparticles are one of the most intensively studied magnetic nanoparticles and can be applied in a variety of areas, ranging from drug delivery [4] and biosensing [5], dynamic sealing [6], and cell labeling [7] to magnetic resonance imaging [8]. Moreover, MNPs are well suited for target capturing, enrichment, and isolation [9]. Accordingly, they can be used for isolating cells [10] and bacteria [11] and for removing environmental toxins such as heavy metals and chemical waste [12].

Research on fluorescent nanomaterials has also gained extensive attention in the past decade. Recently, colloidal semiconductor nanocrystals (quantum dots, QDs) have attracted many researchers due to their broad excitation, size-dependent photoluminescence with narrow emission bandwidth covering a wide spectral range, unusual photochemical stability, and relatively high photoluminescence quantum yield [13]. However, QDs excited by blue or shortwavelength UV radiation can induce autofluorescence of most biological tissues [14], which greatly decreases the sensitivity of detection. Moreover, the risk of systemic toxicity remains high, given their incorporation of heavy metals (e.g., $\mathrm{Pb}, \mathrm{Cd}$ ), precluding their widespread use and ultimate clinical translation [15]. It is perceived that autofluorescence from biomolecules can be avoided if the fluorescent materials can be excited by near-infrared (NIR) or infrared (IR) light [16]. According to the previous reports [17, 18], UCNPs can emit a higher energy photon after absorbing two or more lower energy excitation photons on the basis of sequential adsorption and energy transfer steps, which has a number of advantages, such as low optical background, high photostability, little photodamage to living organisms, and good 
biocompatibility. Over the past decade, high-quality rare earth-doped UCNPs have been successfully synthesized with the rapid development of nanotechnology and are becoming more prominent in biological sciences [19]. The synthesis methods are usually phase-based processes, such as thermal decomposition [20], hydrothermal reaction [21], and ionic liquids-based synthesis [22].

Plant viruses can have a considerable impact on the general public with respect to environment, food supply, and also safety, quality, and diversity of food available. The modern techniques that have been developed for the detection of plant viruses include electron microscopy, serological tests, viral double-stranded RNA analysis, nucleic acid hybridization, polymerase chain reaction (PCR) or reverse transcription (RT)-PCR, and other molecular means. When large numbers of samples have to be handled, double antibody sandwichenzyme-linked immunoabsorbent assay (DAS-ELISA) is the most common [23]. Naturally, every method has its own specificities and limitations. However, the common shortcoming of these methods is that they are usually time-consuming, multistage, and labor-intensive and require highly qualified personnel and sophisticated instrumentation $[24,25]$. Therefore, it is important to develop an easy, sensitive, and readily available detection method for rapid separation and diagnosis of these viruses in plants.

Recent advances in nanotechnology have led to a new class of biological detection method that combines magnetic enrichment and optical detection [26-28]. Although the method has been investigated by some researchers, up to now there is little report on using UCNPs to detect the target. It is predicted that techniques involving novel nanoparticle labels may become one of the effective approaches for the screening of targets in the near future.

In this paper, a simple and convenient method has been put forward to simultaneously detect multiple viruses in plant samples based on antibody-labeled UCNPs coupled with immunomagnetic separation. In the strategy as illustrated in Figure 1, the target viruses firstly are captured by corresponding MNPs modified with different antibodies. And then, three types of antibody-conjugated UCNPs with different emission wavelengths are bound to target viruses. Fluorescence signals with the maximum at 480,540 , and $656 \mathrm{~nm}$, respectively, are corresponding to ToRSV, BPMV, and ArMV. The unbounded viruses and UCNPs are easily washed out in the presence of magnetic field. Hence, the magnetic utilization not only eliminates nonspecific absorption of viruses and reduces fluorescent background but also concentrates trace target viruses resulting in the enhanced fluorescence signals as well. Therefore, selectivity and sensitivity of the approach have been improved.

\section{Materials and Methods}

2.1. Materials. 1-Ethyl-3-(3-dimethylaminopropyl) carbodiimide hydrochloride (EDC), N-hydroxysuccinimide (NHS), and 3-aminopropyltrimethoxysilane (APS) were purchased from Sigma-Aldrich (St. Louis, Mo, US). Anti-ToRSV capture antibody, anti-BPMV capture antibody, anti-ArMV capture antibody, and three kinds of positive plant viruses' samples were obtained from Agdia Inc. (Elkhart, IN, US). The aminofunctionalized silica-coated UCNPs $\left(\mathrm{NH}_{2}-\mathrm{UCNPs} / \mathrm{SiO}_{2}\right)$ with different emission spectra were kindly provided by Prof. Hebai Shen (Shanghai Normal University in China). $\mathrm{NaOH}, \mathrm{FeCl}_{3}, \mathrm{FeSO}_{4}$, glutaraldehyde, and other chemicals were purchased from Sinopharm Chemical Reagent Co., Ltd (Shanghai, China). Deionized water was used throughout.

2.2. Synthesis of $\mathrm{Fe}_{3} \mathrm{O}_{4} / \mathrm{SiO}_{2}$ MNPs. The synthesis of MNPs was prepared according to the reported method [29]. Briefly, the $\mathrm{NaOH}$ solution $(2 \mathrm{M})$ was added to the solution of a mixture of $\mathrm{FeCl}_{3}(0.2 \mathrm{M})$ and $\mathrm{FeSO}_{4}(0.1 \mathrm{M})$ with stirring. The precipitation was aged at $60^{\circ} \mathrm{C}$ for $2-3 \mathrm{~h}$ and washed with water for three times.

2.3. Surface Modification of MNPs. To coat the MNPs with silica, in a $250 \mathrm{~mL}$ flask, $20 \mathrm{mg}$ of MNPs was dispersed in $50 \mathrm{~mL}$ of ethanol by sonication and agitation for $30 \mathrm{~min}$, then $1.7 \mathrm{~mL}$ of ammonia and $1 \mathrm{~mL}$ of water were added to the flask, and the mixture was maintained at $40^{\circ} \mathrm{C}$ under vigorous stirring. A solution containing $10 \mathrm{~mL}$ of ethanol and $0.1 \mathrm{~mL}$ of TEOS was added dropwise to the mixture, and the reaction was continued for $12 \mathrm{~h}$. The precipitate was separated by centrifugation and washed with ethanol three times to obtain $\mathrm{Fe}_{3} \mathrm{O}_{4} / \mathrm{SiO}_{2} \mathrm{MNPs}$. The amino-functionalized $\mathrm{Fe}_{3} \mathrm{O}_{4} / \mathrm{SiO}_{2} \mathrm{MNPs}\left(\mathrm{NH}_{2}-\mathrm{Fe}_{3} \mathrm{O}_{4} / \mathrm{SiO}_{2} \mathrm{MNPs}\right.$ ) were prepared using the same process by adding the solution containing $10 \mathrm{~mL}$ of ethanol and $0.1 \mathrm{~mL}$ of APS slowly to the mixture, followed by the addition of TEOS solution.

2.4. Covalent Immobilization of the Antibody on Surface of the $\mathrm{NH}_{2}-\mathrm{Fe}_{3} \mathrm{O}_{4} / \mathrm{SiO}_{2} \mathrm{MNPs}$. Glutaraldehyde is employed for the conjugation of $\mathrm{NH}_{2}-\mathrm{Fe}_{3} \mathrm{O}_{4} / \mathrm{SiO}_{2}$ MNPs with the corresponding antibodies, as reported previously [30]. Typically, $1 \mathrm{mg}$ of $\mathrm{NH}_{2}-\mathrm{Fe}_{3} \mathrm{O}_{4} / \mathrm{SiO}_{2}$ MNPs was dispersed into phosphate-buffered saline (PBS, $0.01 \mathrm{M}, \mathrm{pH}$ 7.4) containing $5 \%$ glutaraldehyde with shaking for $3 \mathrm{~h}$ at room temperature. The nanoparticles were collected by centrifugation, redispersed in PBS, and then incubated with $0.1 \mathrm{mg} / \mathrm{mL}$ of antiToRSV antibody, anti-BPMV antibody, and anti-ArMV antibody, respectively, for $3 \mathrm{~h}$ at $4^{\circ} \mathrm{C}$. The antibody-conjugated $\mathrm{Fe}_{3} \mathrm{O}_{4} / \mathrm{SiO}_{2}$ MNPs were collected and washed with PBS several times in the presence of an external magnetic field to remove unconjugated antibodies.

\subsection{Preparation of the Antibody-Conjugated $\mathrm{UCNPs} / \mathrm{SiO}_{2}$.} The antibody-conjugated $\mathrm{UCNPs} / \mathrm{SiO}_{2}$ is synthesized following a previous procedure [16]. $0.1 \mathrm{~mL}$ of $0.1 \mathrm{mg} / \mathrm{mL}$ antibody in PBS was mixed with $0.1 \mathrm{~mL}$ of $2 \mathrm{mg} / \mathrm{mL} \mathrm{UCNPs}_{\mathrm{SiO}}$ solution in the same buffer. The mixture was activated by incubating with $0.05 \mathrm{~mL}$ of $0.5 \mathrm{mg} / \mathrm{mL}$ EDC and $0.05 \mathrm{~mL}$ of $0.2 \mathrm{mg} / \mathrm{mL}$ NHS for $15 \mathrm{~min}$, and the reaction was continued for another $2 \mathrm{~h}$ at room temperature under gentle shaking. The antibody-conjugated $\mathrm{UCNPs} / \mathrm{SiO}_{2}$ were purified by centrifugation, washed with PBS three times, and redispersed in PBS.

2.6. Characterization. The size and morphology of $\mathrm{Fe}_{3} \mathrm{O}_{4} /$ $\mathrm{SiO}_{2}$ MNPs were measured on a JEM-2100 transmission 


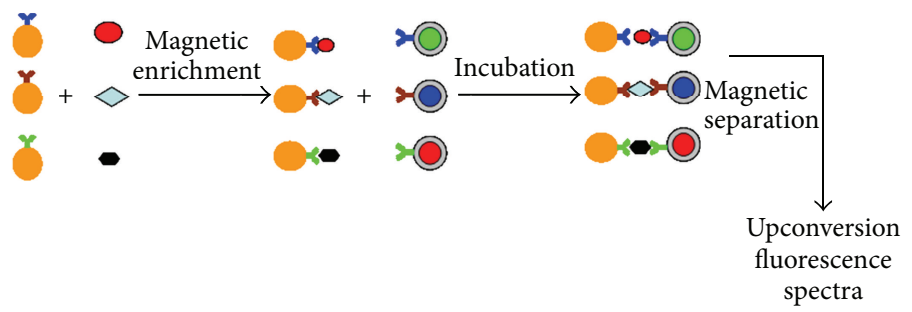

Different antibody-conjugated $\mathrm{SiO}_{2} / \mathrm{Fe}_{3} \mathrm{O}_{4}$ MNPs

Different antibody-conjugated $\mathrm{SiO}_{2} / \mathrm{UCNPS}$

Different kinds of plant virus

FIGURE 1: Schematic illustration of immunomagnetic separation and fluorescence detection of target viruses in sandwich-type system.

electron microscope (TEM, JEOL, Japan), using an accelerating voltage of $200 \mathrm{kV}$. The magnetization of $\mathrm{Fe}_{3} \mathrm{O}_{4} / \mathrm{SiO}_{2}$ MNPs was tested on a JDM-13 vibrating sample magnetometer at $298 \mathrm{~K}$ and $\pm 15 \mathrm{kOe}$ applied magnetic field. Fourier transform infrared (FT-IR) spectra of the nanoparticles were obtained on a Nicolet 370 FTIR spectrophotometer (Thermo, USA). Pressed pellets were prepared by grinding the powder specimens with $\mathrm{KBr}$ in an agate mortar. Upconversion fluorescence spectra of the UCNPs were taken on a Fluorolog3 fluorescence spectrophotometer (Jobin Yvon, Inc., France) attached with an external $980 \mathrm{~nm}$ laser (Beijing Hi-Tech Optoelectronic Co., China).

2.7. Individual Assays. A schematic view of the reaction steps for detection of multiple plant viruses is shown in Figure 1. This is a sandwich-type of detection with the assistance of magnetic force and upconversion fluorescent detection. Three viruses can be first captured specifically by the corresponding antibody-conjugated $\mathrm{Fe}_{3} \mathrm{O}_{4} / \mathrm{SiO}_{2} \mathrm{MNPs}$ to form "MNPs-virus" immunocomplexes. In detail, we made $1 \mathrm{mg} / \mathrm{mL}$ of positive samples by adding $2 \mathrm{~mL}$ deionized water to $2 \mathrm{mg}$ positive controls (lyophilized powder) of each kind of virus from Agdia, and an 8-fold dilution series of each virus $\left(10^{0}, 10^{-1}, 10^{-2}, 10^{-3}, 10^{-4}, 10^{-5}, 10^{-6}, 10^{-7} \mathrm{mg} / \mathrm{mL}\right.$, resp. $)$ was introduced in triplicate into the tubes containing $0.1 \mathrm{~mL}$ of corresponding antibody-conjugated $\mathrm{Fe}_{3} \mathrm{O}_{4} / \mathrm{SiO}_{2} \mathrm{MNPs}$. The mixtures were followed by incubation in a shaker for $45 \mathrm{~min}$ at room temperature. Next, a magnetic field was applied to isolate "MNPs-virus" immunocomplexes. The complexes were then washed with PBS three times and the unbound viruses were discarded. Following target enrichment, $0.1 \mathrm{~mL}$ of the corresponding antibody-conjugated UCNPs $/ \mathrm{SiO}_{2}$ was, respectively, added into the above complexes and then incubated for another $45 \mathrm{~min}$ to form a "MNPs-virus-UCNPs" sandwich format. Free or unbound fluorescent probes were discarded by washing three times with PBS in the presence of the magnetic field. The mixtures were suspended with $1 \mathrm{~mL}$ of PBS. Finally, the fluorescence intensities of these sandwich complexes were measured with a fluorophotometer. Recognition of each virus yields a distinct fluorescent peak, whose position and intensity reflects the identity and the concentrations of the corresponding analytes. To investigate the reproducibility of our assay, we repeatedly assayed 3 times for all different concentrations of viruses.

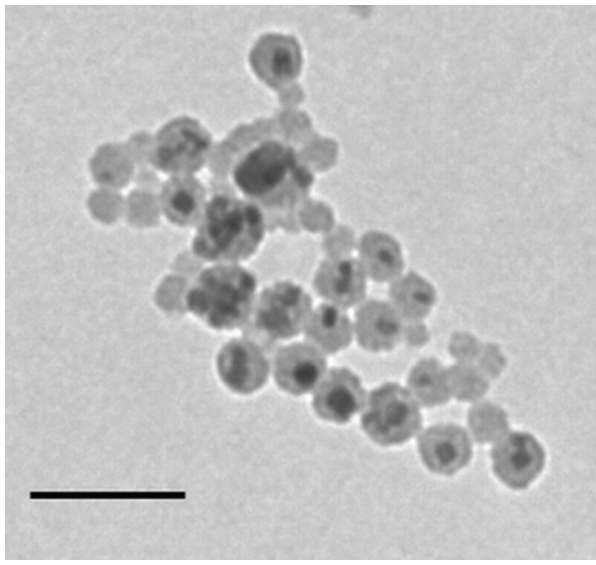

Figure 2: Typical TEM image of $\mathrm{Fe}_{3} \mathrm{O}_{4} / \mathrm{SiO}_{2}$ MNPs. The scale bar in the inset corresponds to $300 \mathrm{~nm}$.

2.8. Multiplex Assays. Multicolor $\mathrm{UCNPs} / \mathrm{SiO}_{2}$ nanoparticles are utilized to identify three groups of plant viruses. Three aliquots of $0.1 \mathrm{~mL}$ of antibody-conjugated $\mathrm{Fe}_{3} \mathrm{O}_{4} / \mathrm{SiO}_{2} \mathrm{MNPs}$ were mixed together to attain the $0.3 \mathrm{~mL}$ assay volume and were used to capture ToRSV, BPMV, and ArMV from the mixed suspensions. "MNPs-virus" immunocomplexes were separated from the mixtures by applying a magnet. Then we added equal amounts of antibody-conjugated UCNPs/SiO from each set to detect simultaneously three viruses in the suspensions.

\section{Results and Discussion}

A TEM image of $\mathrm{Fe}_{3} \mathrm{O}_{4} / \mathrm{SiO}_{2}$ MNPs is showed in Figure 2. The nanoparticles are well-dispersed and spherical in shape, with an average size of about $100 \mathrm{~nm}$, and it can be seen clearly that the $\mathrm{Fe}_{3} \mathrm{O}_{4} / \mathrm{SiO}_{2}$ MNPs have a core-shell structure.

Magnetic measurement shows that the saturation magnetization values of pure $\mathrm{Fe}_{3} \mathrm{O}_{4}$ MNPs and $\mathrm{Fe}_{3} \mathrm{O}_{4} / \mathrm{SiO}_{2}$ MNPs are 63.6 and $33.5 \mathrm{emu} \mathrm{g}^{-1}$, respectively (Figure 3(a)). It should be noted that the $\mathrm{Fe}_{3} \mathrm{O}_{4} / \mathrm{SiO}_{2}$ MNPs still show strong magnetization after coating with $\mathrm{SiO}_{2}$ nanoshell, indicating its suitability for magnetic separation. Moreover, the $\mathrm{Fe}_{3} \mathrm{O}_{4} / \mathrm{SiO}_{2}$ MNPs with homogeneous dispersion were strongly responsive to an external magnetic field, making 


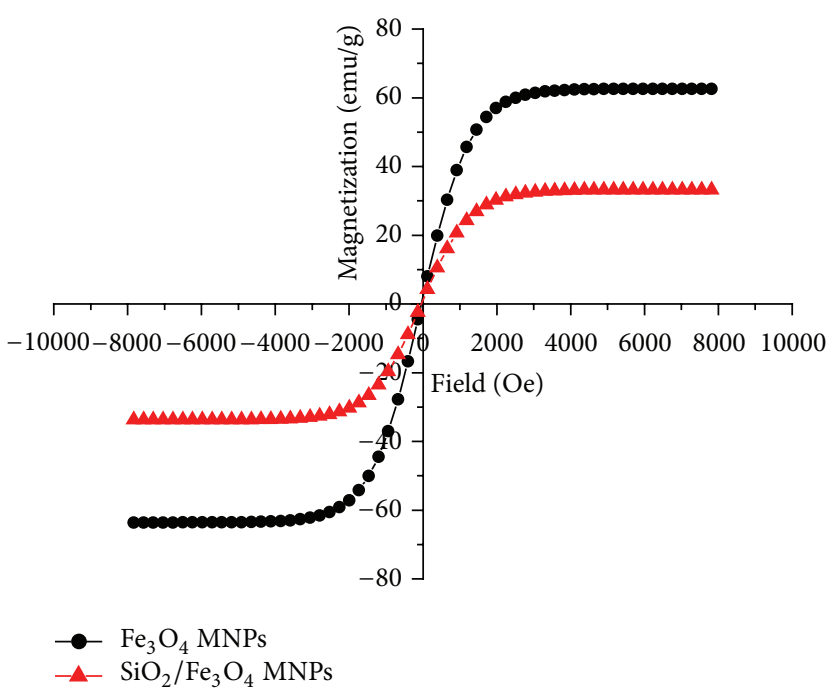

(a)
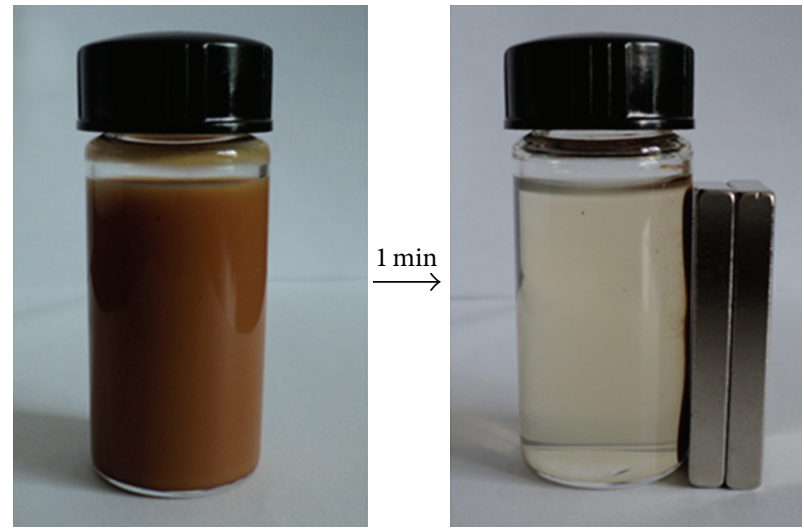

(b)

Figure 3: The magnetic hysteresis loops of $\mathrm{Fe}_{3} \mathrm{O}_{4} \mathrm{MNPs}$ and $\mathrm{Fe}_{3} \mathrm{O}_{4} / \mathrm{SiO}_{2} \mathrm{MNPs}$ (a). The separation process of the $\mathrm{Fe}_{3} \mathrm{O}_{4} / \mathrm{SiO}_{2} \mathrm{MNPs}$ under a permanent magnet $(b)$.

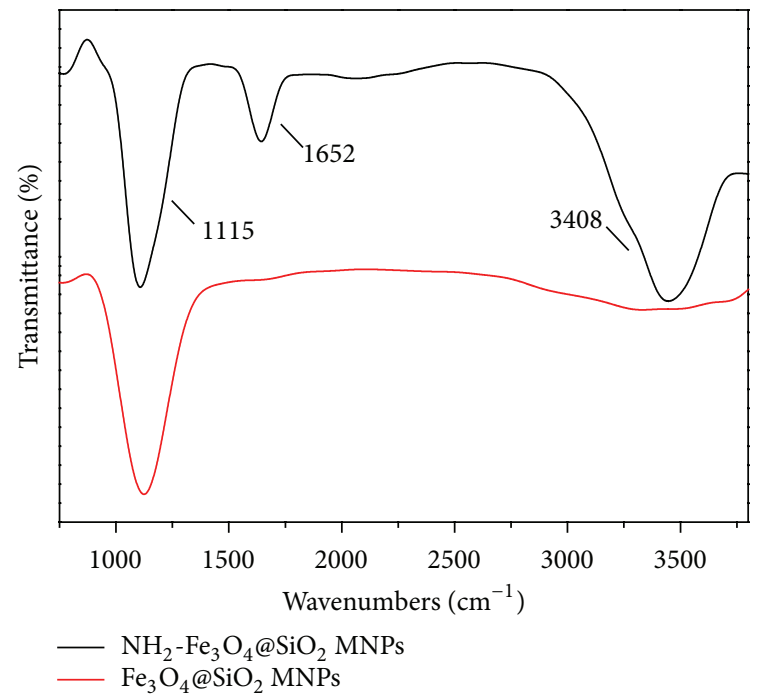

Figure 4: FT-IR spectra of $\mathrm{Fe}_{3} \mathrm{O}_{4} / \mathrm{SiO}_{2} \mathrm{MNPs}$ and $\mathrm{NH}_{2}-\mathrm{Fe}_{3} \mathrm{O}_{4} / \mathrm{SiO}_{2}$ MNPs.

separation from solution possible in less than 1 minute using a permanent magnet (Figure 3(b)).

The surface of the $\mathrm{Fe}_{3} \mathrm{O}_{4} / \mathrm{SiO}_{2}$ MNPs is modified with the amino group, as confirmed from the FT-IR spectra shown in Figure 4. Two peaks associated with the stretching and bending vibration of the amino group $\left(\mathrm{NH}_{2}{ }^{-}\right)$can be found at 3408 and $1652 \mathrm{~cm}^{-1}$, respectively, in the spectrum [31]. In addition, the peak at $1115 \mathrm{~cm}^{-1}$ is assigned to the asymmetry stretching vibration of $\mathrm{Si}-\mathrm{O}$ bond [32]. Based on the above-described results, it can be deduced that the aminofunctionalized $\mathrm{Fe}_{3} \mathrm{O}_{4} / \mathrm{SiO}_{2} \mathrm{MNPs}$ are fabricated successfully.

The upconversion fluorescence property of UCNPs $/ \mathrm{SiO}_{2}$ is investigated at room temperature by using a $980 \mathrm{~nm}$ laser as

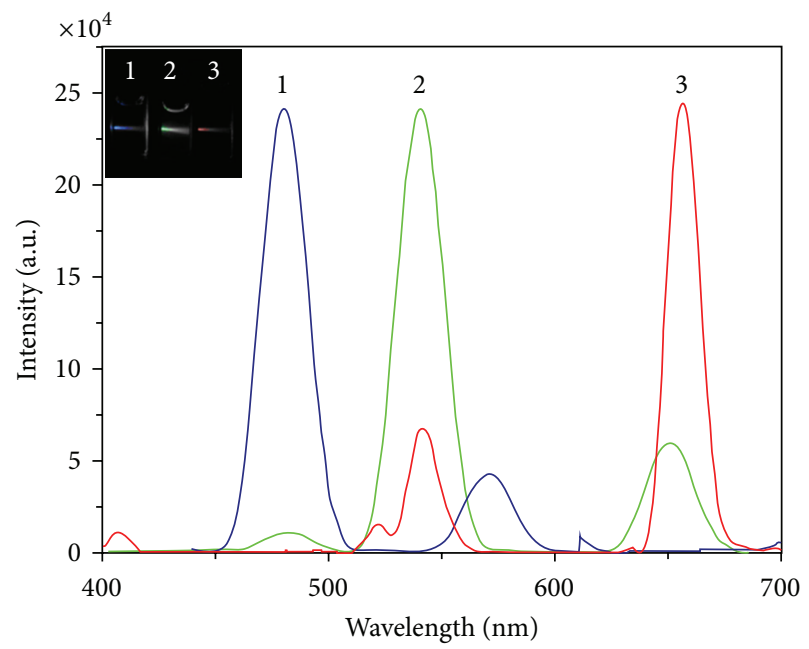

FIGURE 5: Room temperature upconversion fluorescence spectra of three different UCNPs $/ \mathrm{SiO}_{2}$ in PBS under $980 \mathrm{~nm}$ excitation. $\mathrm{NaYbF}_{4}: \mathrm{Tm} / \mathrm{SiO}_{2}$ (curve 1), $\mathrm{NaYbF}_{4}: \mathrm{Ho} / \mathrm{SiO}_{2}$ (curve 2), and $\mathrm{NaYbF}_{4}: \mathrm{Er} / \mathrm{SiO}_{2}$ (curve 3). Inset is the photo of the corresponding $\mathrm{UCNPs} / \mathrm{SiO}_{2}$ in $\mathrm{PBS}$ excited with a $980 \mathrm{~nm}$ laser.

the excitation source. As shown in Figure 5, the upconversion fluorescence spectra of three kinds of $\mathrm{UCNPs} / \mathrm{SiO}_{2}$ display distinctive emission peak patterns (emission maximum at 480, 540, and $656 \mathrm{~nm}$, resp.). Different upconversion luminescence "color" from three types of UCNPs can be easily differentiated in the image without obvious cross-talk (inset in Figure 5).

Figure 6 shows the UV/Vis absorption spectra of pure antibody and antibody-conjugated UCNPs/SiO $\mathrm{U}_{2}$. It is known that the absorption peak of protein can be observed at around $280 \mathrm{~nm}$ [33]. From Figure 6, the absorption spectrum 


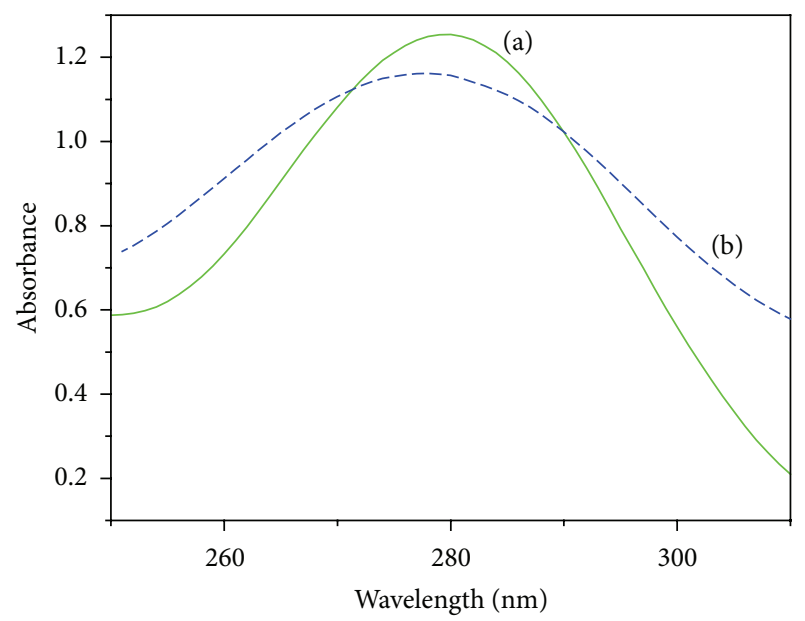

FIGURE 6: UV/Vis absorption spectra of the pure anti-ToRSV antibody (a) and antibody-conjugated UCNPs/SiO 2 (b).

of antibody-conjugated $\mathrm{UCNPs} / \mathrm{SiO}_{2}$ shows a pronounced peak corresponding to pure antibody, indicating that the bioconjugate between UCNPs/SiO 2 and antibody has been successfully formed.

In order to detect three kinds of virus, respectively, different quantities of ToRSV, BPMV, and ArMV, respectively, are chosen as the test samples. The resulting "MNPsvirus" immunocomplexes are used to conjugate $0.1 \mathrm{~mL}$ of the corresponding antibody-conjugated UCNPs $/ \mathrm{SiO}_{2}$ in the further experiments. As $\mathrm{Fe}_{3} \mathrm{O}_{4} / \mathrm{SiO}_{2} \mathrm{MNPs}$ have excellent magnetic property, sandwich complexes can be magnetically purified after immunoreaction to remove the excess antibody-conjugated UCNPs/SiO 2 , and then the immunocomplexes are dispersed in PBS and their fluorescence spectra are recorded at different concentrations of added viruses. As shown in Figure 7, the sequential increases in fluorescence emission are observed when $\mathrm{Fe}_{3} \mathrm{O}_{4} / \mathrm{SiO}_{2} \mathrm{MNPs}$ and $\mathrm{UCNPs} / \mathrm{SiO}_{2}$ are incubated together with increasing content of viruses. In the range of $10^{-4}-10^{0} \mathrm{mg} / \mathrm{mL}$, there is a relatively good linear relationship between the enhanced fluorescence and the concentrations of viruses. Therefore, it is noted that the detection limit of this method for all three of the species is in the order of $10^{-4} \mathrm{mg} / \mathrm{mL}$ by thresholding the signal level higher than the background signal. Interestingly, the increase of fluorescence intensity accelerates at higher concentrations of BPMV (from $10^{-3}$ to $10^{0} \mathrm{mg} / \mathrm{mL}$ ), whereas the intensities of ToRSV and ArMVstill increase at the same slope. This may be due to the steric effect of specific antigen recognition.

In order to study the nonspecific binding of the proposed method, anti-ToRSV antibody-conjugated UCNPs $/ \mathrm{SiO}_{2}$ and "MNPs-BPMV" immunocomplexes are mixed by using the procedure described above. Upconversion fluorescence spectra of the supernatant and resuspended deposit after magnetic separation are shown in Figure 8(a). The prominent emission peak at $480 \mathrm{~nm}$ can be clearly seen in the supernatant, for fluorescent nanoparticles are unable to identify immunocomplexes, and meanwhile, the weak fluorescence emission can also be detected from the deposit, demonstrating that there is a low level of nonspecific binding

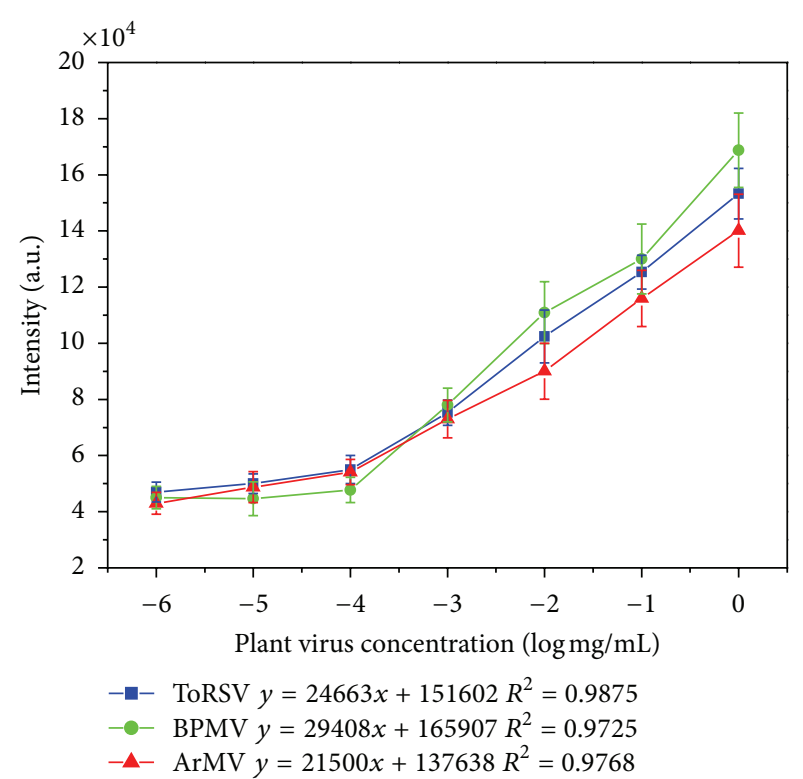

FIGURE 7: Intensities of fluorescence peaks at 480,540, and $656 \mathrm{~nm}$, respectively, as produced by different concentrations of ToRSV, BPMV, and ArMV after magnetic separation. The results are obtained from three independent experiments.

of anti-ToRSV antibody-conjugated $\mathrm{UCNPs} / \mathrm{SiO}_{2}$ to the "MNPs-BPMV" immunocomplexes. On the other hand, anti-ToRSV antibody-conjugated UCNPs/SiO 2 and "MNPsToRSV" immunocomplexes are mixed under the same condition and the fluorescence spectra of supernatant and deposit after magnetic separation are shown in Figure 8(b). The peak at $480 \mathrm{~nm}$ can be observed in fluorescence spectra of the deposit due to the specific antibody-antigen interaction between antibody-conjugated $\mathrm{UCNPs} / \mathrm{SiO}_{2}$ and virus on the $\mathrm{Fe}_{3} \mathrm{O}_{4} / \mathrm{SiO}_{2}$ MNPs surface.

To demonstrate the practical viability of this method in simultaneously detecting multiple viruses in a plant matrix, three classes of immunonanoparticles are incubated with the mixed solutions containing three viruses with different concentrations. After incubation, these immunocomplexes are separated by means of an external magnetic field. The three target viruses can be measured independently in a single sample by obtaining the signals at 480,540, and $656 \mathrm{~nm}$, respectively. The calibration graph for the multiplex fluoroimmunoassay is presented in Figure 9. It can be observed that the multiplex curves are very similar to those seen in Figure 7 for the corresponding single virus assays. Moreover, the expansion of assay multiplicity does not result in any loss of assay specificity or sensitivity, indicating the high specificity of antibodies. Background signals may be generated by the nonspecific binding between magnetic nanoparticles and fluorescence nanoparticles. As low as $10^{-4} \mathrm{mg} / \mathrm{mL}$ of ToRSV, BPMV and ArMV may be clearly distinguished from the background signals, suggesting that our approach is applicable to the simultaneous detection of multiple targets with unchanged selectivity.

This study aims to demonstrate a proof of concept of combining UCNPs as biolabeling with immunomagnetic 


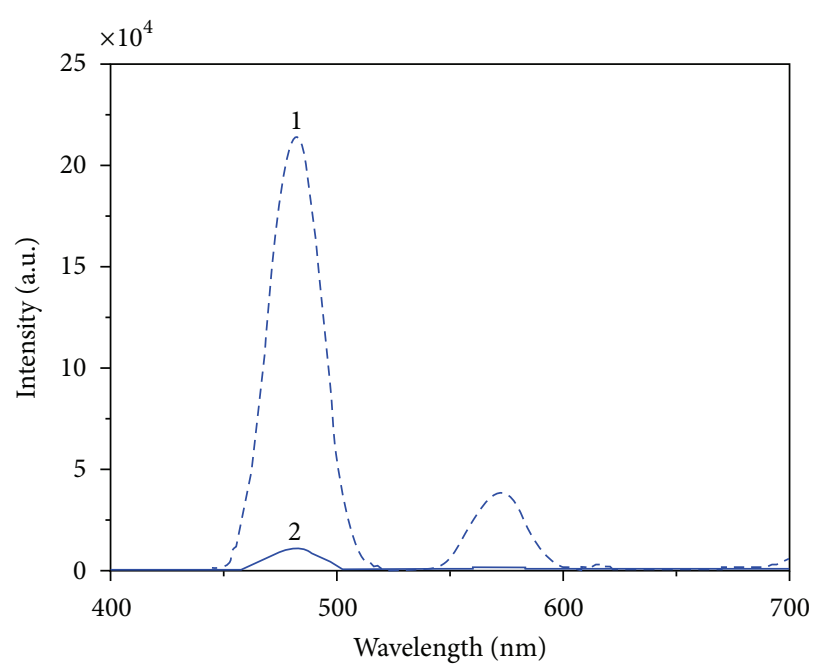

(a)

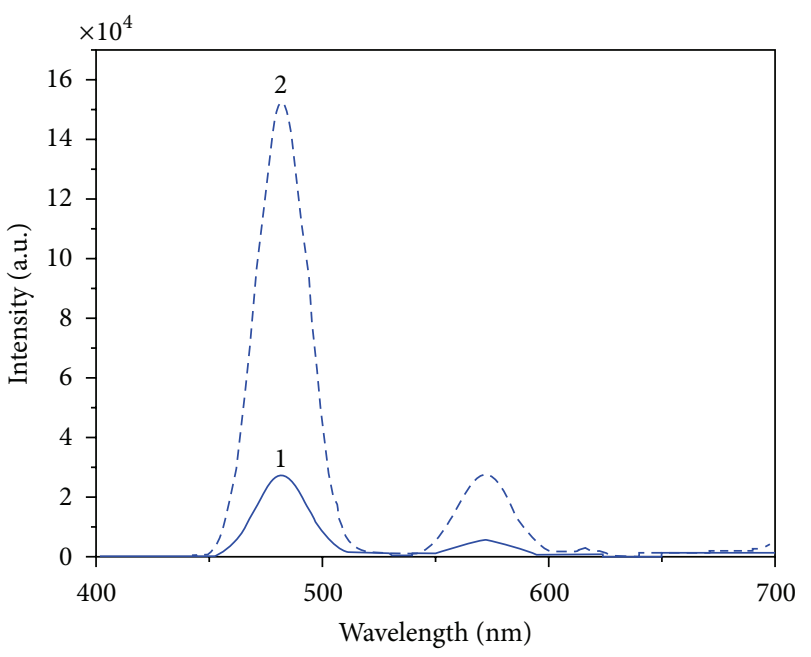

(b)

FIGURE 8: Upconversion fluorescence spectra obtained after anti-ToRSV antibody-conjugated UCNPs/SiO 2 and "MNPs-BPMV" immunocomplexes are mixed: the fluorescence spectra of the supernatant (curve 1) and the resuspended deposit (curve 2) after magnetic separation (a); upconversion fluorescence spectra obtained after anti-ToRSV antibody-conjugated UCNPs $/ \mathrm{SiO}_{2}$ and "MNPs-ToRSV" immunocomplexes are mixed: the fluorescence spectra of the supernatant (curve 1) and the resuspended deposit (curve 2) after magnetic separation (b).

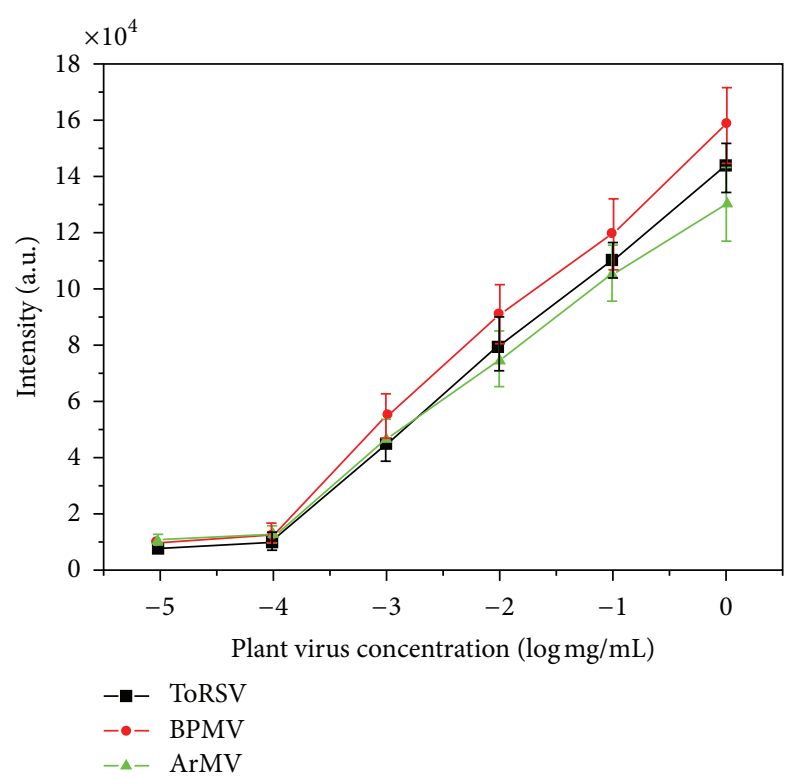

Figure 9: Multiplex immunoassay for ToRSV, BPMV, and ArMV. The results are obtained from three independent experiments.

separation for the detection of plant virus. Hence, no effort has been made for extensive parametric optimization. However, this assay is easy to perform and the entire process can be achieved within $2.5 \mathrm{~h}$ of arrival of the sample in the laboratory.

\section{Conclusion}

In summary, we report the proof of concept of a simple and sensitive multiplexed immunoassay system for simultaneous determination of three different plant viruses withcombining magnetic enrichment and optical detection. Compared with conventional method, the highlights of this work can be summarized as follows: (i) different types of antibodies can be immobilized on different MNPs and thus simultaneously capture multiple viruses; (ii) UCNPs of different emission profiles can be excited at the same time. This unique property makes it possible to detect different emission peaks simultaneously excited with a single wavelength; (iii) the conventional procedure is relatively laborious and timeconsuming. Our method, of which the detection procedure is completed within $2.5 \mathrm{~h}$, can separate and concentrate the target viruses to a detectable level by a nongrowth step; and (iv) the method may be more convenient and comfortable to use than PCR which is a multistep protocol that requires (1) high-quality RNA purification, (2) optimal conversion of RNA to cDNA, and (3) sensitive and accurate real-time detection of PCR products, which all need to be completed by highly qualified personnel and several steps must be taken to prevent and minimize PCR contamination including the use of aerosol barrier tip filters, laminar flow cabinet, and a special preparation area for PCR separate from the DNA isolation area. In a word, these features make it a valuable tool for a wide range of biotechnology applications.

\section{Acknowledgments}

This research was supported by AQSIQ Grant (no. 2011IK249), national science foundation of Zhejiang province (no. Y3090211), program for science and technology from Zhejiang province (no. 2011C22065), and program for science and technology from Zhejiang entry-exit inspection and quarantine bureau (no. ZK200957; ZK200958; ZK201310). 


\section{References}

[1] K. K. Jain, "Nanotechnology in clinical laboratory diagnostics," Clinica Chimica Acta, vol. 358, no. 1-2, pp. 37-54, 2005.

[2] T. Osaka, T. Matsunaga, T. Nakanishi, A. Arakaki, D. Niwa, and H. Iida, "Synthesis of magnetic nanoparticles and their application to bioassays," Analytical and Bioanalytical Chemistry, vol. 384, no. 3, pp. 593-600, 2006.

[3] G. Wang, Q. Peng, and Y. Li, "Lanthanide-doped nanocrystals: synthesis, optical-magnetic properties, and applications," Accounts of Chemical Research, vol. 44, no. 5, pp. 322-332, 2011.

[4] O. Veiseh, J. W. Gunn, and M. Zhang, "Design and fabrication of magnetic nanoparticles for targeted drug delivery and imaging," Advanced Drug Delivery Reviews, vol. 62, no. 3, pp. 284-304, 2010.

[5] L. Yang, X. Ren, F. Tang, and L. Zhang, "A practical glucose biosensor based on $\mathrm{Fe}_{3} \mathrm{O}_{4}$ nanoparticles and chitosan/nafion composite film," Biosensors and Bioelectronics, vol. 25, no. 4, pp. 889-895, 2009.

[6] P. Ripka, "New directions in fluxgate sensors," Journal of Magnetism and Magnetic Materials, vol. 215, pp. 735-739, 2000.

[7] C. Wilhelm and F. Gazeau, "Universal cell labelling with anionic magnetic nanoparticles," Biomaterials, vol. 29, no. 22, pp. 31613174, 2008.

[8] T. K. Jain, S. P. Foy, B. Erokwu, S. Dimitrijevic, C. A. Flask, and V. Labhasetwar, "Magnetic resonance imaging of multifunctional pluronic stabilized iron-oxide nanoparticles in tumor-bearing mice," Biomaterials, vol. 30, no. 35, pp. 6748-6756, 2009.

[9] A. Agrawal, T. Sathe, and S. Nie, "Single-bead immunoassays using magnetic microparticles and spectral-shifting quantum dots," Journal of Agricultural and Food Chemistry, vol. 55, no. 10, pp. 3778-3782, 2007.

[10] X. Liang, K. Xu, J. Xu, W. Chen, H. Shen, and J. Liu, "Preparation of immunomagnetic nanoparticles and their application in the separation of mouse CD $34^{+}$hematopoietic stem cells," Journal of Magnetism and Magnetic Materials, vol. 321, no. 12, pp. 18851888, 2009.

[11] Z. Shan, Q. Wu, X. Wang et al., "Bacteria capture, lysate clearance, and plasmid DNA extraction using $\mathrm{pH}$-sensitive multifunctional magnetic nanoparticles," Analytical Biochemistry, vol. 398, no. 1, pp. 120-122, 2010.

[12] Y. F. Shen, J. Tang, Z. H. Nie, Y. D. Wang, Y. Ren, and L. Zuo, "Preparation and application of magnetic $\mathrm{Fe}_{3} \mathrm{O}_{4}$ nanoparticles for wastewater purification," Separation and Purification Technology, vol. 68, no. 3, pp. 312-319, 2009.

[13] I. L. Medintz, H. T. Uyeda, E. R. Goldman, and H. Mattoussi, "Quantum dot bioconjugates for imaging, labelling and sensing," Nature Materials, vol. 4, no. 6, pp. 435-446, 2005.

[14] O. Ehlert, R. Thomann, M. Darbandi, and T. Nann, "A fourcolor colloidal multiplexing nanoparticle system," ACS Nano, vol. 2, no. 1, pp. 120-124, 2008.

[15] X. Song, F. Li, J. Ma, N. Jia, J. Xu, and H. Shen, "Synthesis of fluorescent silica nanoparticles and their applications as fluorescence probes," Journal of Fluorescence, vol. 21, no. 3, pp. 12051212, 2011.

[16] M. Wang, C. Mi, Y. Zhang et al., "NIR-responsive silica-coated $\mathrm{NaYbF} 4: \mathrm{Er} / \mathrm{Tm} / \mathrm{Ho}$ upconversion fluorescent nanoparticles with tunable emission colors and their applications in immunolabeling and fluorescent imaging of cancer cells," Journal of Physical Chemistry C, vol. 113, no. 44, pp. 19021-19027, 2009.

[17] S. Gai, P. Yang, C. Li et al., "Synthesis of magnetic, up-conversion luminescent, and mesoporous core-shell-structured nanocomposites as drug carriers," Advanced Functional Materials, vol. 20, no. 7, pp. 1166-1172, 2010.

[18] M. Yu, F. Li, Z. Chen et al., "Laser scanning up-conversion luminescence microscopy for imaging cells labeled with rareearth nanophosphors," Analytical Chemistry, vol. 81, no. 3, pp. 930-935, 2009.

[19] J. Chen and J. X. Zhao, "Upconversion nanomaterials: synthesis, mechanism, and applications in sensing," Sensors, vol. 12, no. 3, pp. 2414-2435, 2012.

[20] J. C. Boyer, L. A. Cuccia, and J. A. Capobianco, "Synthesis of colloidal upconverting NaYF4: $\mathrm{Er}^{3+} / \mathrm{Yb}^{3+}$ and $\mathrm{Tm}^{3+} / \mathrm{Yb}^{3+}$ monodisperse nanocrystals," Nano Letters, vol. 7, no. 3, pp. 847-852, 2007.

[21] C. Li, Z. Quan, J. Yang, P. Yang, and J. Lin, "Highly uniform and monodisperse $\beta$-NaYF4: $\mathrm{Ln}^{3+}(\mathrm{Ln}=\mathrm{Eu}, \mathrm{Tb}, \mathrm{Yb} / \mathrm{Er}$, and $\mathrm{Yb} / \mathrm{Tm})$ hexagonal microprism crystals: hydrothermal synthesis and luminescent properties," Inorganic Chemistry, vol. 46, no. 16, pp. 6329-6337, 2007.

[22] X. Liu, J. Zhao, Y. Sun et al., "Ionothermal synthesis of hexagonal-phase NaYF4: $\mathrm{Yb}^{3+}, \mathrm{Er}^{3+} / \mathrm{Tm}^{3+}$ upconversion nanophosphors," Chemical Communications, no. 43, pp. 6628-6630, 2009.

[23] Z. Du, B. Jin, W. Liu, L. Chen, and J. Chen, "Highly sensitive fluorescent-labeled probes and glass slide hybridization for the detection of plant RNA viruses and a viroid," Acta Biochimica et Biophysica Sinica, vol. 39, no. 5, pp. 326-334, 2007.

[24] Y. B. Tang, D. Xing, D. B. Zhu, and J. F. Liu, "An improved electrochemiluminescence polymerase chain reaction method for highly sensitive detection of plant viruses," Analytica Chimica Acta, vol. 582, no. 2, pp. 275-280, 2007.

[25] L. M. Wright, J. T. Kreikemeier, and C. J. Fimmel, "A concise review of serum markers for hepatocellular cancer," Cancer Detection and Prevention, vol. 31, no. 1, pp. 35-44, 2007.

[26] Y. J. Liu, D. J. Yao, H. Y. Chang, C. M. Liu, and C. Chen, "Magnetic bead-based DNA detection with multi-layers quantum dots labeling for rapid detection of Escherichia coli O157:H7," Biosensors and Bioelectronics, vol. 24, no. 4, pp. 558-565, 2008.

[27] M. Nichkova, D. Dosev, S. J. Gee, B. D. Hammock, and I. M. Kennedy, "Multiplexed immunoassays for proteins using magnetic luminescent nanoparticles for internal calibration," Analytical Biochemistry, vol. 369, no. 1, pp. 34-40, 2007.

[28] Y. Zhao, C. Hao, W. Ma et al., "Magnetic bead-based multiplex DNA sequence detection of genetically modified organisms using quantum dot-encoded silicon dioxide nanoparticles," Journal of Physical Chemistry C, vol. 115, no. 41, pp. 20134-20140, 2011.

[29] H. Shen, Y. Wang, H. Yang, and J. Jiang, "Covalent immobilization of oligoDNA on the surface of magnetic nanoparticles and surface-enhanced Raman scattering study," Chinese Science Bulletin, vol. 48, no. 24, pp. 2698-2702, 2003.

[30] H. H. Yang, S. Q. Zhang, X. L. Chen, Z. X. Zhuang, J. G. Xu, and X. R. Wang, "Magnetite-containing spherical silica nanoparticles for biocatalysis and bioseparations," Analytical Chemistry, vol. 76, no. 5, pp. 1316-1321, 2004.

[31] X. Liu, J. Xing, Y. Guan, G. Shan, and H. Liu, "Synthesis of amino-silane modified superparamagnetic silica supports and their use for protein immobilization," Colloids and Surfaces A, vol. 238, no. 1-3, pp. 127-131, 2004.

[32] J. Zhang and R. D. K. Misra, "Magnetic drug-targeting carrier encapsulated with thermosensitive smart polymer: core-shell nanoparticle carrier and drug release response," Acta Biomaterialia, vol. 3, no. 6, pp. 838-850, 2007. 
[33] J. Ma, Q. Fan, L. Wang, N. Jia, Z. Gu, and H. Shen, "Synthesis of magnetic and fluorescent bifunctional nanocomposites and their applications in detection of lung cancer cells in humans," Talanta, vol. 81, no. 4-5, pp. 1162-1169, 2010. 

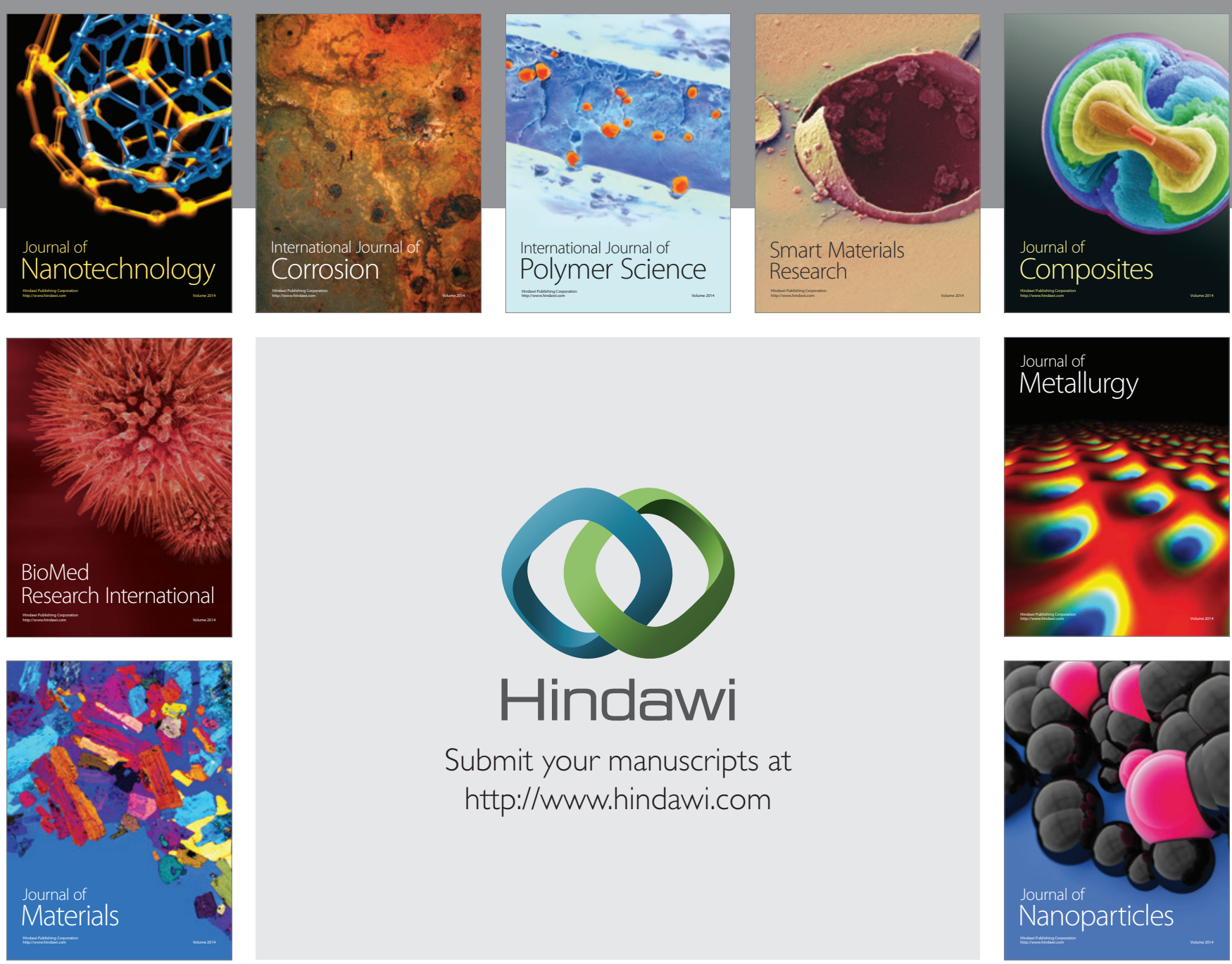

Submit your manuscripts at http://www.hindawi.com
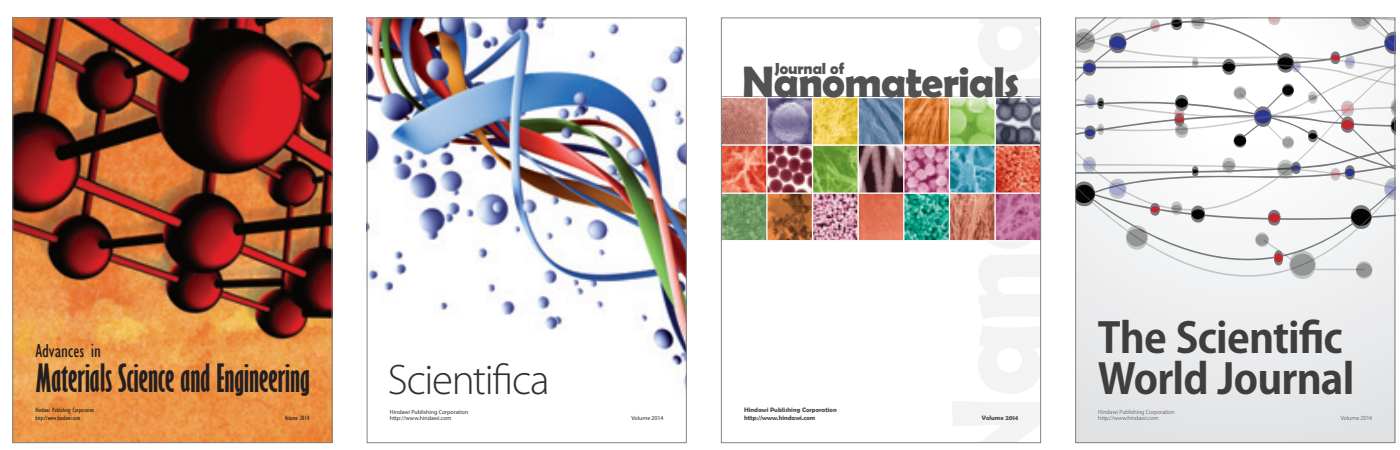

\section{The Scientific World Journal}
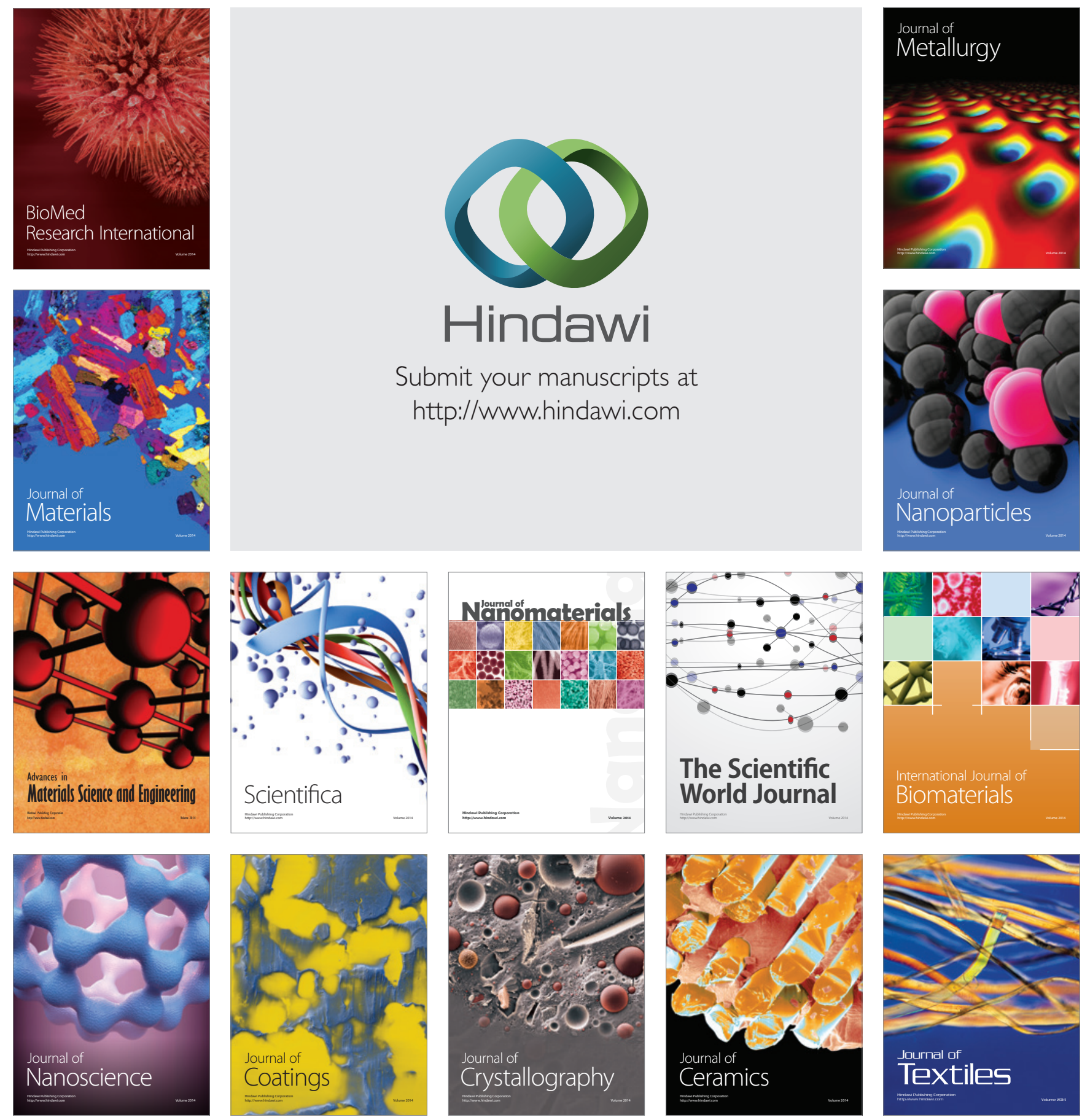